\title{
A Política Externa Brasileira e o Grupo dos Brics
}

\author{
Ivan Filipe de Almeida Lopes Fernandes* \\ Luís Fernando de Paiva Baracho Cardoso**
}

\section{Resumo}

Este artigo tem o duplo objetivo de analisar o processo de formação da coalizão BRICS (Brasil, Rússia, Índia, China e África do Sul), apresentando os seus principais estágios de formação e suas proposições; bem como o de compreender se a política externa brasileira foi alterada (ou não) a partir da formação desta coalizão internacional. Analisamos o processo de formação a partir da possibilidade de os BRICS tornarem-se um novo polo de poder autônomo no sistema internacional. Apesar de existirem críticas a respeito da coesão dos interesses e orientações internacionais deste grupo, há evidências que demonstram um esforço de suas lideranças na elaboração de uma agenda internacional comum e na discussão dos padrões hegemônicos que orientam a governança econômica internacional. Analisamos os efeitos do surgimento do grupo BRICS na política externa brasileira a partir da análise dos padrões de votação do Brasil na Assembleia Geral da ONU (AGONU). O objetivo é observar se, além do discurso diplomático, o comportamento internacional do Brasil foi alterado com a configuração institucional do grupo. Para tanto, discutimos quais foram os efeitos da formação dos BRICS na política externa brasileira a partir da convergência entre os padrões de votação do Brasil e de seus parceiros na AG-ONU. Concluímos, enfim, que o surgimento dos BRICS não teve o impacto esperado na política externa brasileira. Os padrões de convergência pouco diferem entre período anterior e o posterior à formação do grupo.

Palavras-chave: BRICS, Política Externa Brasileira, Padrões de Votação na Assembléia Geral da ONU

\section{Abstract}

\section{Brazilian Foreign Policy and the Brics}

This article aims at i) analyse the development process of the international coalition named BRICS (Brazil, Russia, India, China and South Africa), presenting its landmarks and propositions; ii) to identify if the Brazilian foreign policy has changed (or not) after it. We analyse the BRICS bearing in mind its possibility to become a new international powerhouse. Despite some critics regarding the convergence of its members's interests there is enough evidence to show an attempt of its members to forge a new agenda as well as a discussion about the old structure of international governance. In order to establish a correlation between Brazil's foreign policy with the BRICS we analyse the Brazilian voting pattern in the UN General Assembly (UNGA). By doing that we try to define if BRICS-led diplomacy is actually taking place in the UNGA or if it's more about diplomatic rhetoric. We have concluded that Brazilian foreign policy has not changed significantly after the BRICS since it's voting patterns mildly change.

Keywords: BRICS, Brazilian Foreign Policy, UNGA Voting Patterns

\footnotetext{
* Universidade Federal do ABC / Centro de Engenharia, Modelagem e Ciências Sociais Aplicadas - São Bernardo do Campo / SP, Brasil. Email: ivan.fernandes@ufabc.edu.br.

** Professor Associado da Escola de Direito das FMU/ SP, Brasil. Email: luis.cardoso@fmu.br.
} 


\section{Introdução ${ }^{1}$}

Este artigo tem o duplo objetivo de analisar o processo de formação da coalizão BRICS (Brasil, Rússia, Índia, China e África do Sul), apresentando os seus principais estágios de formação, suas proposições; bem como o de compreender se a política externa brasileira foi alterada (ou não) a partir da formação desta coalizão internacional.

Analisamos o processo de formação a partir da possibilidade de os BRICS tornarem-se um novo polo de poder autônomo no sistema internacional. Apesar de existirem críticas a respeito da coesão dos interesses e orientações internacionais deste grupo, há evidências que demonstram um esforço de suas lideranças na elaboração de uma agenda internacional comum e na discussão dos padrões hegemônicos que orientam a governança econômica internacional.

Kissinger (1999) em sua obra de referência, "Diplomacia", analisa a importância das coalizões internacionais em pentarquia nos séculos XIX (i.e., o Concerto Europeu, decorrente do Congresso de Viena, formado por Áustria, França, Prússia, Reino Unido e Rússia) e no século XX (seja nos membros permanentes do Conselho de Segurança da Organização das Nações Unidas, seja na composição original do G7). Nesse sentido, nos parece interessante o fato de, mais uma vez, emergir um modelo de coalizão em pentarquia, cuja dinâmica, agenda e possibilidades estão ainda em desenvolvimento; tal modelo apresenta uma grande oportunidade ao Brasil a fim de que possa ter uma inserção internacional assertiva e que extrapole o seu contexto regional.

De acordo com Andrew Hurrel (2009), há quatro motivos fundamentais para o estudo dos países desta coalizão. Em primeiro lugar, todos parecem dispor, em algum nível, de recursos de poder militar, político e econômico, alguma capacidade de contribuir para a gestão da ordem internacional em termos regionais ou globais, além de algum grau de coesão interna e capacidade de ação estatal efetiva. Em segundo lugar, todos compartilham de uma crença em seu direito a um papel mais influente em assuntos mundiais, pois possuem poder

\footnotetext{
${ }^{1}$ Os autores agradecem aos comentários e contribuições feitas pelos dois pareceristas anônimos, pelos colegas Laerte Apolinário Júnior e Bruno Mariotto Jubran e por Guilherme Fernandes, Vinicius Albino de Freitas e Paulo Watanabe que participaram de mesa no V Congreso Uruguayo de Ciência Política no qual versão anterior deste trabalho foi apresentada. Os comentários foram essenciais e melhoraram significativamente o artigo. Quaisquer erros e omissões remanescentes são de responsabilidade dos autores.
} 


\section{Leviathan | Cadernos de Pesquisa Política}

N. 11, pp.121-144, 2015

econômico para demandar a revisão da ordem estabelecida, de maneira a refletir seus próprios interesses. Em terceiro lugar, a iniciativa por parte desses países de estabelecer relações cooperativas entre si, como a emergência do grupo dos 20 na Organização Mundial do Comércio, a criação da coalizão de países do sul liderada por Brasil, Índia e África do Sul, sob a forma do fórum IBAS; a expansão das relações econômicas chinesas com Índia e Brasil; além da formalização do bloco BRICS com a ocorrência de reuniões anuais por parte dos chefes de Estado destes países².

O texto está dividido em três seções, além desta Introdução. Na próxima seção, introduzimos brevemente a história do acrônimo, discutimos a relevância econômica dos BRICS e em seguida a evolução política do grupo como uma coalizão com potencial poder no sistema internacional. Por fim, apresentamos as principais criações internacionais dos BRICS, gestadas ao longo das últimas reuniões de cúpula e que tomaram corpo institucional na 6a reunião de cúpula, realizada em julho de 2014. Na seção seguinte, analisamos quais foram os efeitos do surgimento deste grupo para a política externa brasileira a partir dos padrões de votação do Brasil na Assembleia Geral da ONU (AG-ONU). O objetivo desta seção é observar, se além do discurso diplomático, o comportamento internacional do Brasil foi alterado com a configuração institucional do grupo. Finalmente, na terceira e última seção concluímos a análise.

\section{A importância global dos Brics}

O conceito de BRIC foi formulado pelo então economista chefe do Grupo Financeiro Goldman Sachs, Jim O'Neill, em estudo de 2001, intitulado “Building Better Global Economic $B R I C s^{\prime \prime}{ }^{3}$, no qual O'Neill vislumbrava uma alteração no equilíbrio do poder econômico internacional com o crescimento acelerado das economias emergentes de Brasil, Rússia, Índia e China (O’NEILL, 2001). Em 2009, na reunião de cúpula realizada em Ecaterimburgo (Rússia) ${ }^{4}$, este acrônimo econômico deu origem a um agrupamento político internacional com grande potencial, incorporando à política externa de Brasil, Rússia, Índia e China a temática de

\footnotetext{
${ }^{2}$ Agradecemos a Laerte Apolinário Júnior pela indicação da referência.

${ }^{3}<$ http://www.goldmansachs.com/our-thinking/archive/archive-pdfs/build-better-brics.pdf>, Acesso em 10.04.2015.

${ }^{4}<$ http://archive.kremlin.ru/eng/text/docs/2009/06/217963.shtml>, Acesso em 10.04.2015.
} 
reforma das instituições de governança global. Em 2011, por ocasião da 3a reunião de cúpula realizada em Sanya (China) $)^{5}$, a África do Sul passou a fazer parte do agrupamento, que adotou a sigla BRICS (HERTZ E DUTRA, 2013).

As nações do acrônimo alcançaram visibilidade pelo desempenho superior em termos de crescimento e desenvolvimento econômico, o que trouxe à tela a hipótese de que neste novo século o crescimento da economia global será baseado no crescimento das economias emergentes ${ }^{6}$. E como consequência, seria possível vislumbrar uma redefinição da arquitetura das instituições econômicas internacionais de modo a atualizá-la aos novos atores que emergem e poderão controlar num futuro próximo boa parte dos fluxos de comércio, produção e investimento (LIMA, 2010).

Da discussão acadêmica e econômica, surgiu uma movimentação política por parte destes países que, à luz da defesa de uma reformulação das instituições internacionais de governança econômica, demandam uma revisão do sistema elaborado no pós-guerra, apontando a necessidade de adaptá-lo às novas realidades econômicas. As leituras predominantemente econômicas deram espaço para uma discussão sobre as reinvindicações políticas que expressam as necessidades de mudanças nos regimes internacional de governança política, monetária, comercial e econômica global, como o FMI, o Banco Mundial e o próprio Conselho de Segurança da Organização das Nações Unidas (CS-ONU) (HERTZ E DUTRA, 2013).

Nesse sentido, a redução da proeminência do G-7 - o fórum que agrupa as principais economias desenvolvidas: Estados Unidos, Japão, Reino Unido, Alemanha, França, Itálica e Canadá - como fórum máximo de coordenação e governança econômica internacional passou a ser um dos eixos centrais da cooperação entre os BRICS (HERTZ E DUTRA, 2013)7.

\footnotetext{
${ }^{5}<$ http://www.gov.cn/misc/2011-04/14/content_1844551.htm>, Acesso em 10.04.2015

6 O que alguns chamam de "a ascensão do resto" (the rise of the rest) (ZAKARIA, 2008).

${ }^{7}$ É interessante estabelecer um paralelismo com a formação do Grupo dos 7, pois o número de membros não se manteve sempre o mesmo e a sua agenda também oscilou conforme o tempo. O G7 foi estabelecido em 17 de novembro de 1975 na Cúpula de Rambouillet (França), entre Alemanha Ocidental, Estados Unidos, França, Itália, Japão e Reino Unido. Tal reunião teve como predecessores a reunião do então G5 financeiro (Alemanha Ocidental, Estados Unidos, França, Japão e Reino Unido) em 1973, como consequência da crise econômica daquele ano. O Canadá foi incorporado em 1976 e as Comunidade Europeia em 1977. Em 1998, depois de anos participando como convidada, a Rússia foi incorporada ao grupo. Em 2005, na Cúpula de Gleneagles (Reino Unido), foi realizado o "outrach dialogue" entre o G8 e um novo "G5" (África do Sul, Brasil, China, Índia e México). A agenda de trabalho do G8 nunca foi monotemática, incorporando temas como sistema financeiro
} 


\section{Leviathan | Cadernos de Pesquisa Política}

N. 11, pp.121-144, 2015

Ao longo deste processo de formação inicial, as características de institucionalização dos BRICS mudaram desde a criação da sigla. Em seu primeiro momento, havia apenas diálogos em nível ministerial e, subsequentemente, o diálogo alcançou os líderes dos quatro estados fundadores da coalizão - Brasil, Rússia, Índia e China; e em seguida a África do Sul se somou ao esforço de reorganização do mapa geoeconômico do sistema internacional (BIJOS E GUILHON, 2014). Tal institucionalização, contudo, não muda a natureza jurídica dos BRICS que continuam não sendo uma organização internacional, mas antes um arranjo institucional informal diante do direito internacional.

\section{A evolução do processo de entendimento}

A crescente importância dos BRICS nas decisões econômicas internacionais decorre dos esforços efetivos destes países em acelerar o seu crescimento e desenvolvimento econômico e das expectativas de que nas próximas décadas a realização do potencial crescimento dos BRICS terá como consequência a reconfiguração multipolar do poder econômico e político dentro das instituições de governança econômica do sistema internacional.

À vista da modificação da realidade internacional nos últimos anos, aponta-se para um aprofundamento da crise de legitimidade na tomada de decisões internacionais pelas potências ocidentais a partir da incapacidade de apenas as economias europeias e norte americanas, somadas à japonesa, controlarem os principais fluxos de investimento, comércio e produção econômica. Na visão de Stuenkel (2012) o BRICS é uma das mais inesperadas e inovadoras criações da nova estrutura de governança internacional, com demanda de revisão da estrutura econômica e política global que não eram possíveis e imagináveis no imediato pós-Guerra Fria.

Atualmente, a pauta principal e unificadora da agenda dos BRICS é uma demanda por maior participação nas instituições internacionais, com a inclusão dos países do Sul liderados pelos próprios BRICS - nos principais fóruns de debate e decisão sobre a arquitetura das instituições econômicas internacionais. Além do argumento da reconfiguração da

internacional, comércio internacional, meio ambiente, combate ao terrorismo, energia, etc. O objetivo sempre foi de coordenar a atuação dos seus membros em vários fóruns internacionais da forma mais flexível possível (KIRTON, 2008 e RAMOS, 2014). 


\section{Leviathan | Cadernos de Pesquisa Política}

N. 11, pp.121-144, 2015

geografia econômica global, a demanda principal dos BRICS é a incorporação, de maneira crível, de suas demandas e preocupações econômicas internacionais às principais instituições econômicas internacionais, reduzindo a proeminência americana e europeia nos principais fóruns como o Banco Mundial, o Fundo Monetário Internacional - FMI e o sistema multilateral de comércio GATT/OMC.

Como agrupamento, o processo de formação dos BRICS teve em seus estágios iniciais um caráter nitidamente informal, com poucas tentativas de construção de conexões institucionais sólidas no campo da economia internacional, considerando ainda o fato de que as economias dos países membros não eram e ainda não são integradas. $O$ grupo não foi estabelecido de forma solene por meio de tratado, não possuindo uma sede, secretariado fixo, personalidade jurídica internacional ou mesmo fundos comuns destinados ao financiamento das atividades do grupo.

Em última análise, pode-se dizer que o que sustenta o mecanismo de interlocução internacional é a vontade política de seus membros, a partir de uma percepção generalizada da necessidade de adequação da arquitetura institucional multilateral. As lideranças políticas dos cinco países participantes têm feito esforços conjuntos para encontrar denominadores comuns, possíveis complementaridades e possibilidades de atuação conjunta, tanto como cooperação econômica quanto reformatação da arquitetura institucional do sistema internacional (BAUMANN, 2010).

A integração foi realizada nos seguintes passos: em 2006, os ministros das relações exteriores do Brasil, Rússia, Índia e China se encontraram na cidade de Nova lorque em paralelo às reuniões da AG-ONU. A partir deste encontro uma série de reuniões de alto nível foram realizadas até que em 2008 aconteceu a primeira Reunião de Cúpula com a presença dos respectivos chefes de estado - Dmitry Medvedev (Rússia), Luiz Inácio Lula da Silva (Brasil), Hu Jintao (China) e Manmohan Singh (Índia) - em Ecaterimburgo, na Rússia, onde vários temas relacionados à crise econômica financeira, tais como comércio internacional, o papel do dólar como moeda de reserva e a participação nos organismos internacionais, foram discutidos.

Em seguida, foram realizadas anualmente outras reuniões de cúpula. A segunda ocorreu em 2010 em Brasília (Brasil), a terceira em 2011 em Sanya (China), a quarta em 2012 


\section{Leviathan | Cadernos de Pesquisa Política}

N. 11, pp.121-144, 2015

em Nova Déli (Índia), a quinta em 2013 em Durban (África do Sul) e a sexta em 2014 em Fortaleza (Brasil).

Na $6^{a}$ Reunião em Fortaleza (Brasil) foram criados os dois primeiros frutos institucionais do Grupo: o Novo Banco de Desenvolvimento (NBD) e o Arranjo Contingente de Reserva (CRA). Estes últimos representam novas alternativas na arquitetura econômica internacional em relação às principais instituições de Bretton Woods (Banco Mundial e FMI), que ainda hoje são as principais instituições do sistema econômico internacional e cujo processo decisório está nitidamente relacionado com os interesses econômicos estadunidenses e europeus. De forma que a influência dos BRICS em suas decisões, sobretudo no sistema de votação do FMI, é bastante baixa (Apolinário, 2014) ${ }^{8}$. Na tabela 1 listamos as principais reuniões dos BRICS.

Tabela 1. Reuniões de Cúpula dos BRICS

\begin{tabular}{|c|c|c|c|c|c|}
\hline & $\begin{array}{c}\text { Cidade - } \\
\text { Sede }\end{array}$ & País & Ano & Membros & Convidados \\
\hline $\begin{array}{c}1 a \\
\text { Cúpula }\end{array}$ & Ecaterimburgo & Rússia & 2009 & Brasil, Russia, Índia e China & \\
\hline $\begin{array}{c}2 a \\
\text { Cúpula }\end{array}$ & Brasília & Brasil & 2010 & Brasil, Russia, Índia e China & $\begin{array}{c}\text { África do Sul e Autoridade } \\
\text { Palestina }\end{array}$ \\
\hline $\begin{array}{c}3 a \\
\text { Cúpula }\end{array}$ & Sanya & China & 2011 & $\begin{array}{c}\text { Brasil, Russia, Índia, China e } \\
\text { África do Sul }\end{array}$ & \\
\hline $\begin{array}{c}4 a \\
\text { Cúpula }\end{array}$ & Nova Déli & Índia & 2012 & $\begin{array}{c}\text { Brasil, Russia, Índia, China e } \\
\text { África do Sul }\end{array}$ & \\
\hline $\begin{array}{c}5 a \\
\text { Cúpula }\end{array}$ & Durban & $\begin{array}{l}\text { África do } \\
\text { Sul }\end{array}$ & 2013 & $\begin{array}{c}\text { Brasil, Russia, Índia, China e } \\
\text { África do Sul }\end{array}$ & \\
\hline $\begin{array}{c}6 a \\
\text { Cúpula }\end{array}$ & Fortaleza & Brasil & 2014 & $\begin{array}{c}\text { Brasil, Russia, Índia, China e } \\
\text { África do Sul }\end{array}$ & $\begin{array}{l}\text { Argentina } \\
\text { e líderes da UNASUL }\end{array}$ \\
\hline
\end{tabular}

i - Bolívia, Chile, Colômbia, Equador, Guiana, Paraguai, Peru, Suriname, Uruguai e Venezuela

Apontamos ainda que na reunião de Fortaleza, além do encontro dos BRICS, o Brasil organizou paralelamente uma reunião da União das Nações Sulamericanas - UNASUL, de modo a promover uma aproximação qualificada entre os países sul-americanos com os

\footnotetext{
${ }^{8}$ Agradecemos a um dos pareceristas por ter-nos apontado o papel da falta de influência dos BRICS nas votações do FMI como um dos elementos fomentadores do grupo.
} 


\section{Leviathan | Cadernos de Pesquisa Política}

N. 11, pp.121-144, 2015

principais emergentes, além de legitimar a liderança regional brasileira. Ainda que não seja possível avaliar as consequências internacionais da aproximação do bloco dos BRICS e da UNASUL promovida pelo Brasil, fica claro como a diplomacia brasileira busca conectar os diferentes fóruns de diálogos multilaterais dos quais faz parte.

Aos poucos os BRICS vêm galgando um grau maior de institucionalização, tendo se consolidado nos últimos dez anos à medida que os cinco países intensificam sua interação nesta série de reuniões de cúpula. Ademais, além das reuniões de cúpulas, inúmeras reuniões ministeriais preparatórias são realizadas com o objetivo de criação de uma agenda internacional mínima que fortaleça o grupo em face das outras potencias econômicas internacionais e aumente o grau de conhecimento político - administrativo mútuo entre os operadores econômicos e políticos dos governos envolvidos.

\section{Os BRICS dentro do sistema econômico financeiro internacional}

Uma tensão existente no processo de consolidação do grupo é o papel proeminente tomado pela China. A principal motivação da articulação política dos BRICS é aumentar sua capacidade de barganha frente às antigas potências econômicas da Europa, EUA e Japão. Contudo, o acelerado crescimento econômico da China e o aumento cada vez maior da sua capacidade industrial de inovação tecnológica tem dado ao gigante asiático a capacidade de uma inserção internacional autônoma, inclusive de modo a utilizar o próprio fórum dos BRICS como um mecanismo de favorecimento de seus objetivos nacionais.

Em 2011 os cinco países do grupo perfazem, segundo dados de PIB real em paridade do poder de compra $^{9}$, cerca de $28 \%$ de toda a produção econômica global, enquanto o G-7 produz $38 \%$ do produto global. Mais importante, as tendências de evolução destes indicadores são invertidas. No gráfico 1 apresentamos dados sobre a participação dos BRICS e do G-7 na economia global desde 1991.Incluímos também as participações dos dois maiores países de cada um dos grupos - respectivamente, China e EUA - e a participação brasileira.

Em 1991, o G-7 possuía cerca de $48 \%$ da economia global, enquanto o futuro BRICS detinha apenas $20 \%$. Os EUA por si só eram responsáveis por $22 \%$ enquanto a China o era por

\footnotetext{
${ }^{9}$ Penn Word Tables - versão 8.0
} 


\section{Leviathan | Cadernos de Pesquisa Política}

N. 11, pp.121-144, 2015

$7 \%$ e o Brasil por 2.3\%. Nos anos 2000 , esses dados haviam mudado muito pouco. Os BRICS detinham apenas 19\%, enquanto o G-7 mantinha cerca de 49\%. A participação americana subira para $23.5 \%$, a chinesa para $9 \%$ e a brasileira para $2.7 \%$.

Em 2011, último ano para o qual temos dados de PIB real em paridade do poder de compra, o cenário já é bem distinto, o que indica que a dinâmica principal a partir da qual o grupo dos BRICS começa a se organizar são os eventos econômicos e políticos que surgem após a virada do milênio. Neste último ano, a participação dos BRICS no PIB global cresceu para $28 \%$, enquanto a participação do G-7 foi reduzida para $38 \%$. Os EUA viram sua participação na economia global cair para $18.5 \%$, enquanto a China cresceu para $15 \%$. Por fim, o Brasil viu sua participação no PIB mundial reduzida em 0.2 ponto percentual - indo para $2.5 \%$.

No Gráfico 1 apresentamos os dados para os dois grupos, China, Estados Unidos e Brasil. Fica evidente uma tendência positiva de crescimento da participação dos BRICS na produção econômica global a partir de 2001, em uma tendência bastante semelhante ao crescimento da participação da economia chinesa, enquanto a produção brasileira permaneceu nas duas décadas em torno de $2.5 \%$ e $3.5 \%$ da produção mundial. O ápice da participação produtiva do Brasil na economia global foi em 1996, quando $3.5 \%$ do produto mundial foi elaborado no território brasileiro. Na década de 2000, há apenas uma pequeníssima variação da participação brasileira restrita ao intervalo entre $2.5 \%$ e $2.7 \%$ do PIB mundial. 


\section{Leviathan | Cadernos de Pesquisa Política}

N. 11, pp.121-144, 2015

Gráfico 1 - Participação dos BRICS, G-7 e países selecionados no PIB real global

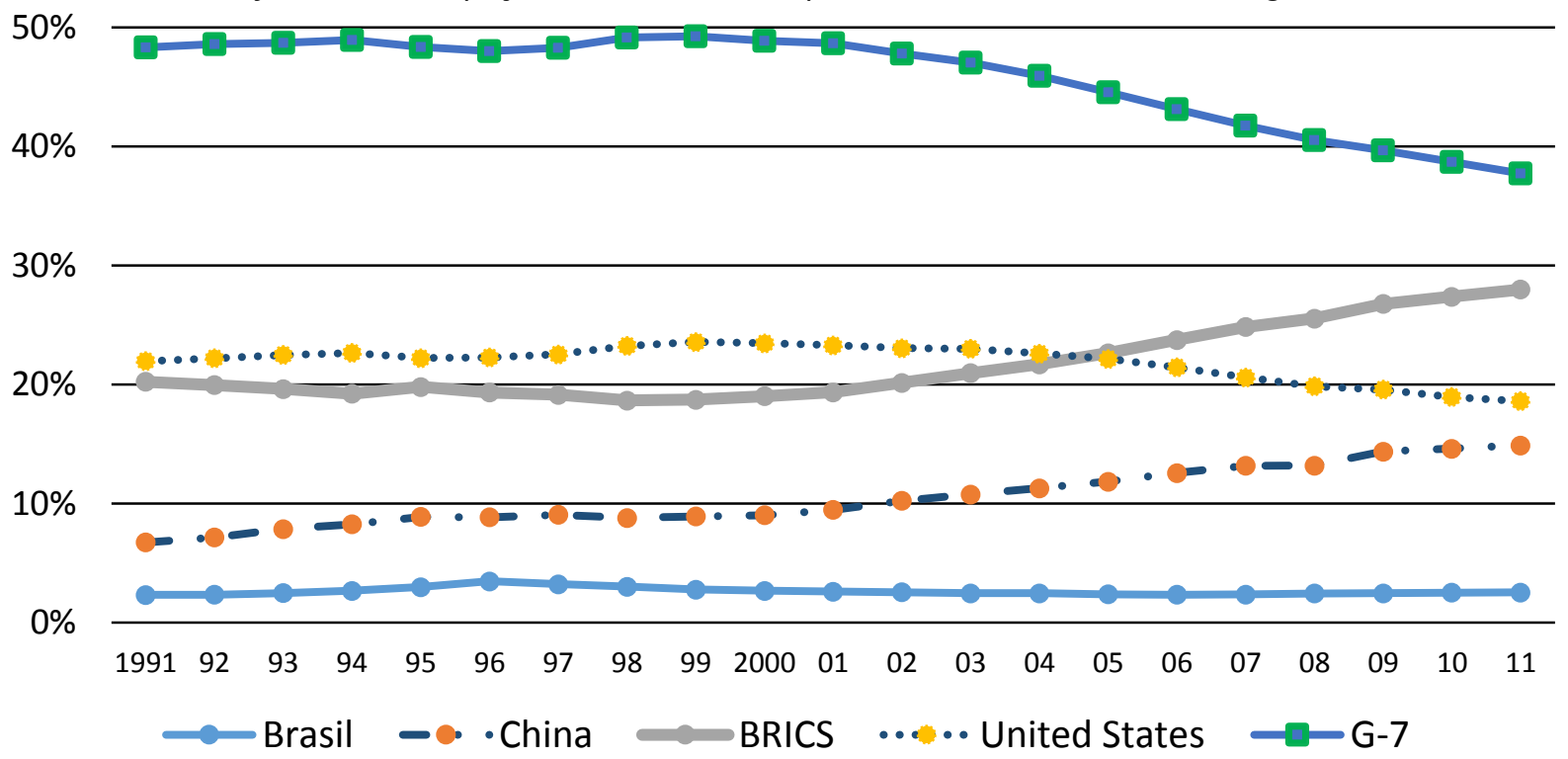

Fonte: Penn Word Tables.

Por outro lado, tanto a economia americana quanto a soma da produção de todos os países do G-7 apresentaram uma participação decrescente na economia global. No ano de 2006, a soma das produções dos BRICS passa pela primeira vez a economia americana e, em 2011, a diferença entre as produções americana e chinesa é de apenas 3.7 pontos percentuais. Ramos (2014) chega à mesma conclusão a respeito da crescente relevância dos países emergentes membros dos BRICS e do G-20 financeiro para o funcionamento da economia global, o que tem como consequência tornar a inclusão destes novos atores nos mecanismos de governança econômica internacional algo cada vez mais impreterível.

No Gráfico 1 fica evidente, sobretudo com os dados a partir dos anos 2000 que o país responsável pela proeminência dos BRICS no cenário internacional é a China. Em 2011, nada menos do que 53\% do PIB dos BRICS é produção chinesa. E em 2000, esta proporção já era próxima: $47.5 \%$ do PIB. No G-7 o predomínio americano é semelhante. Em 2011, cerca de 49\% do PIB real do G-7 era produção americana e em 2000 esse valor era de cerca de 48\%.

Por outro lado, conforme vemos na próxima seção, a crescente proeminência chinesa dentro dos BRICS ainda não teve impacto e nem alterou a afinidade das políticas externa do grupo. Aparentemente os BRICS ainda mantêm-se como uma coalizão que servem aos desígnios internacionais dos seus cinco países membros.

\section{As criações institucionais}




\section{Leviathan | Cadernos de Pesquisa Política}

N. 11, pp.121-144, 2015

O Arranjo Contingente de Reserva (CRA) é um fundo de estabilização da ordem de US\$ 100 bilhões em reservas dividas pelos respectivos Bancos Centrais dos países do BRICS, cujo principal objetivo é prover recursos de emergência durante crises nos balanços de pagamentos de quaisquer um dos seus membros. De fato, o CRA é um fundo coordenado entre os BCs estabelecido para dar mútua liquidez em tempos de crise aos países do grupo. A contribuição da China para o fundo é de US\$ 41 bi, enquanto Brasil, Índia e Rússia contribuíram com US\$ 18 bi cada e a África do Sul com US\$ 5 bi, sendo que a contribuição chinesa não irá exceder $50 \%$ do fundo. A eventual liberação dos recursos se dará por meio de operações de swap, pelas quais o país solicitante receberá dólares e em contrapartida fornecerá sua moeda aos países contribuintes, em montante e por período determinados (GUIMARÃES, 2014).

O funcionamento do CRA é paralelo ao $\mathrm{FMI}$, embora sua capacidade de empréstimo seja ainda bastante inferior. O CRA complementa a rede de proteção financeira mundial, que conta atualmente com organismos financeiros multilaterais, como o FMI, acordos financeiros regionais e acordos bilaterais de swap, além das reservas internacionais dos países. Antes da crise de 2008, o FMI detinha uma capacidade de US\$ 250 bilhões enquanto em 2014 este valor alcançou US\$ 1 trilhão. Assim, CRA ainda possui dotação de recursos bastante inferior à capacidade do FMI para o exercício do papel de emprestador de última instância no sistema financeiro internacional.

Por sua vez, o Novo Banco de Desenvolvimento (NBD) é uma estrutura institucional internacional desenvolvida para financiar o investimento em infraestrutura e em projetos de desenvolvimento sustentável nos BRICS e em outras economias emergentes. É uma instituição concorrente com o Banco Mundial e será dotada inicialmente de US\$ 50 bi para incentivar o crescimento econômico, sendo que cada um dos membros contribuirá com US\$ $10 \mathrm{bi}$. A atual capacidade financiadora do Banco Mundial é também de US\$ 50 bi por ano (GUIMARÃES, 2014), o que aumenta a importância do perfil do NBD.

O banco terá sua sede em Xangai, na China, e seu primeiro presidente será indiano. 0 Brasil deverá indicar o presidente do Conselho de Administração e à Rússia caberá nomear o presidente do Conselho de Governadores. O Centro Regional Africano da instituição será sediado na África do Sul. O NBD deverá também impulsionar ainda mais o comércio entre os 


\section{Leviathan | Cadernos de Pesquisa Política}

N. 11, pp.121-144, 2015

cinco componentes do grupo, que já movimenta cerca de US\$ 54 bilhões anuais.

Diante da crise de legitimidade das instituições financeiras internacionais foi a proposição de novas instituições concorrentes ao sistema de Bretton Woods na reunião do G-20 financeiro em Los Cabos, México, em 2012, seguida de seu efetivo estabelecimento concreto na reunião dos BRICS em Fortaleza, Brasil, em 2014.

\section{Os Brics e a política externa brasileira - transformações e continuidades}

A participação do Brasil nos BRICS e no G-20 financeiro aumentou substancialmente o papel brasileiro nos assuntos globais, assim como a percepção de seu papel no mundo (STUENKEL, 2012). Após a redemocratização, sobretudo a partir do governo Cardoso, a política externa brasileira optou por uma maior participação nos fóruns internacionais. A literatura tradicional indica que houve uma inserção mais alinhada aos EUA entre 1995-2000 e de forma mais autônoma a partir da 2 ㅇ metade do 2 ㅇ mandato de FHC e em todo o período dos governos petistas de Lula e Dilma (FONSECA, 1998; VIGEVANI e CEPALUNI, 2007). A partir do governo Lula, o Brasil teria adotado, inclusive, uma postura mais assertiva em busca de um assento permanente no CS-ONU e os BRICS tornara-se em um importante canal de veiculação destas demandas (STUENKEL, 2012).

A aproximação do Brasil com os polos emergentes de poder foi uma construção política da diplomacia brasileira. Entre os países dos BRICS, a China e a Rússia possuem uma posição mais consolidada no sistema de segurança internacional, fruto de decisões e desdobramentos da Guerra Fria, enquanto que o Brasil, Índia e África do Sul demandam maior participação nessa seara. Não por coincidência, estas três potências emergentes colaboram simultaneamente no fórum IBAS, além da intermediação dos BRICS. O IBAS foi um dos primeiros passos da extensão da cooperação Sul-Sul. Somente em seguida, no contexto da crise financeira internacional, o esforço de aproximação com os emergentes se voltou para a categoria produzida pelo conceito BRICS (LIMA, 2010).

Entre todos os atores do IBAS e BRICS, apenas o Brasil e África do Sul buscam uma 


\section{Leviathan | Cadernos de Pesquisa Política}

N. 11, pp.121-144, 2015

integração a partir apenas do soft power. O caso brasileiro reflete as intenções de um país que articula ambição global de prestígio e influência na governança global sem a correspondente capacidade militar convencional significante e/ou com posse de armas nucleares (STUENKEL, 2012). Desta forma, a dependência da estratégia brasileira do fortalecimento de esferas multilaterais torna os BRICS como um building block fundamental da sua pretendida inserção e ascensão internacional (STUENKEL, 2012; FLEMES, 2010).

Por outro lado, alguns autores como Stuenkel (2014a, b) e Cornetet (2014) indicam que o processo de integração brasileira às instituições de cooperação foi contido com a transição de governo de Lula para Dilma. O perfil político da então presidenta brasileira é mais orientado para questões internas e inclusive o próprio Ministério das Relações Exteriores (MRE) teve sua tradicional proeminência nas instituições administrativas do governo federal reduzida

Na visão de Stuenkel (2014b) durante o governo Dilma houve uma contenção dos objetivos da política externa brasileira em comparação com o governo Lula, algo que o segundo autor define como contenção na continuidade. As iniciativas do Brasil teriam sido nestes últimos anos mais reativas aos problemas internacionais e mais focadas no âmbito das ideias do que da ação prática. Entre as causas levantadas, Stuenkel (2014b) observa que a presidenta Dilma Rousseff considerava a política externa como um campo suscetível a polêmicas e de pouca utilidade em sua busca pela reeleição. Inclusive, na visão do autor, em nenhum outro governo do período democrático brasileiro, o MRE - historicamente considerado acima da disputa política - foi tão secundário no processo decisório em política externa. 


\section{Leviathan | Cadernos de Pesquisa Política}

N. 11, pp.121-144, 2015

\section{Metodologia}

Além do discurso terceiro-mundista, recuperado pelo governo Lula e mantido, ainda que de forma mais contida pelo governo Dilma, é necessário verificar qual é de fato o comportamento da Brasil face os outros países do sistema internacional.

Para avaliar empiricamente se houve alguma mudança a partir da criação dos BRICS como fórum internacional de cooperação em 2006, analisamos, seguindo a metodologia adotada por Oliveira e Onuki (2013), o perfil de similaridade e diferença das votações entre o Brasil e os outros países do BRICS, do G-7 e da UNASUL na AG-ONU. Para tal, utilizamos os dados de Voeten (2012) e Voeten et al (2013) no qual são copilados o grau de afinidade entre todos países na AG-ONU, já que esse seria o principal fórum internacional em que praticamente todos os Estados estão presentes e discutem os principais assuntos da agenda internacional.

Muitos pesquisadores utilizam dados deste tipo, já que não há muitas opções para a avaliação empirica e objetiva do comportamento internacional dos países. Costa (2014) relata que Lijphart (1963), Marín-Bosch $(1987,1998)$ e Selcher $(1978)$ usam as votações na AG-ONU para avaliar a posição dos países em temas multilaterais e em seus alinhamentos regionais, enquanto Thacker (1999), Tomlin (1985) e Voeten (2000) empregam essas votações como indicadores da orientação mais geral da política externa dos Estados. A própria autora utilizou os dados das votaçoes na AG-ONU para analisar o alinhamento da política externa brasileira com os países africanos (Costa, 2014). Ferdinand (2014) também faz uso destes dados para analisar a convergência entre pares e conjuntos de países como os BRICS, os paises desenvolvidos e membros permanentes do Conselho de Segurança da ONU ${ }^{10}$.

Além do mais, a AG-ONU é o único fórum em que um grande número de Estados se encontra e vota em bases regulares sobre assuntos concernentes a diversos temas e questões concernentes à comunidade internacional. Portanto, o estudo dessa votação em um longo período pode revelar possíveis mudanças nos comportamentos dos Estados no sistema internacional (Voeten, 2000), bem como sobre modificações no campo das políticas externas

\footnotetext{
${ }^{10}$ Ferdinand (2014) mostra grande estabilidade na convergência entre os grupos de países na ONU ao longo do período 1974 - 2008. Entre estes grupos, o autor analisa a convergência de todos países membros da Assembleia Geral, Movimento dos Não - Alinhados, G-77, BRICS, IBSA, os membros permanentes do Conselho de Segurança e a tríade Estados Unidos, França e Reino Unido. Agradecemos a um dos pareceristas pela indicação deste artigo.
} 


\section{Leviathan | Cadernos de Pesquisa Política}

N. 11, pp.121-144, 2015

nacionais.

Selecionamos os países da UNASUL como forma de comparação com os resultados do G-7 e dos BRICS. A análise cobre o período posterior ao fim da Guerra Fria, iniciando-se de fato a partir de 1991. A década de 1990 é um período anterior à emergência dos BRICS como instrumento e fórum de concertação internacional e também anterior à adoção de um discurso centrado nas relações Sul-Sul como elemento norteador da política externa brasileira. Tal como no trabalho de Oliveira e Onuki (2013), procuramos ver o peso específico destas diferentes coalizões como um elemento indutor ou não da convergência entre o Brasil e os agrupamentos internacionais.

O grau de afinidade varia de -1 , quando os padrões de votação são exatamente antagônicos, até +1 , quando os padrões são exatamente similares. Os padrões de similaridade são calculados para duas variáveis: similaridade-1 e similaridade-2. A primeira é codificada apenas para duas categorias de voto - 1= sim e 2=não. Já a variável similaridade2 é codificada

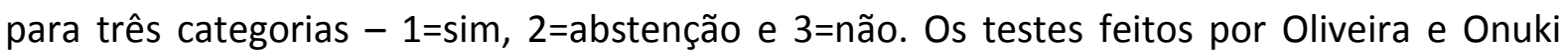
(2013) demonstram que as variáveis são altamente correlacionadas e não há perdas importantes ao tomar as duas variáveis como equivalentes. Contudo, apresentamos resultados de ambas.

A partir das categorias de voto estabelecidas, o cálculo das variáveis é feito a partir da seguinte fórmula:

(1) Similaridade $=1-\frac{2 * d}{d \max }$

onde " $d$ " é a soma métrica das distâncias entre os votos de uma díade (o Brasil com um outro país, em nosso estudo) e "dmax" é a máxima distância possível para aqueles votos.

\section{Resultados}

A partir dos dados individualizáveis de cada uma das díades - isto é a afinidade do Brasil com cada um dos países pertencentes a um dos três grupos selecionados, observamos as 


\section{Leviathan | Cadernos de Pesquisa Política}

médias de cada um dos três grupos: BRICS, G-7 e UNASUL ${ }^{11}$. O Gráfico 2 apresenta os dados de similaridade-1 e o Gráfico 3 os dados de similaridade-2.

Gráfico 2 - Média de Similaridade-1 na AG-ONU entre os Grupos com o Brasil

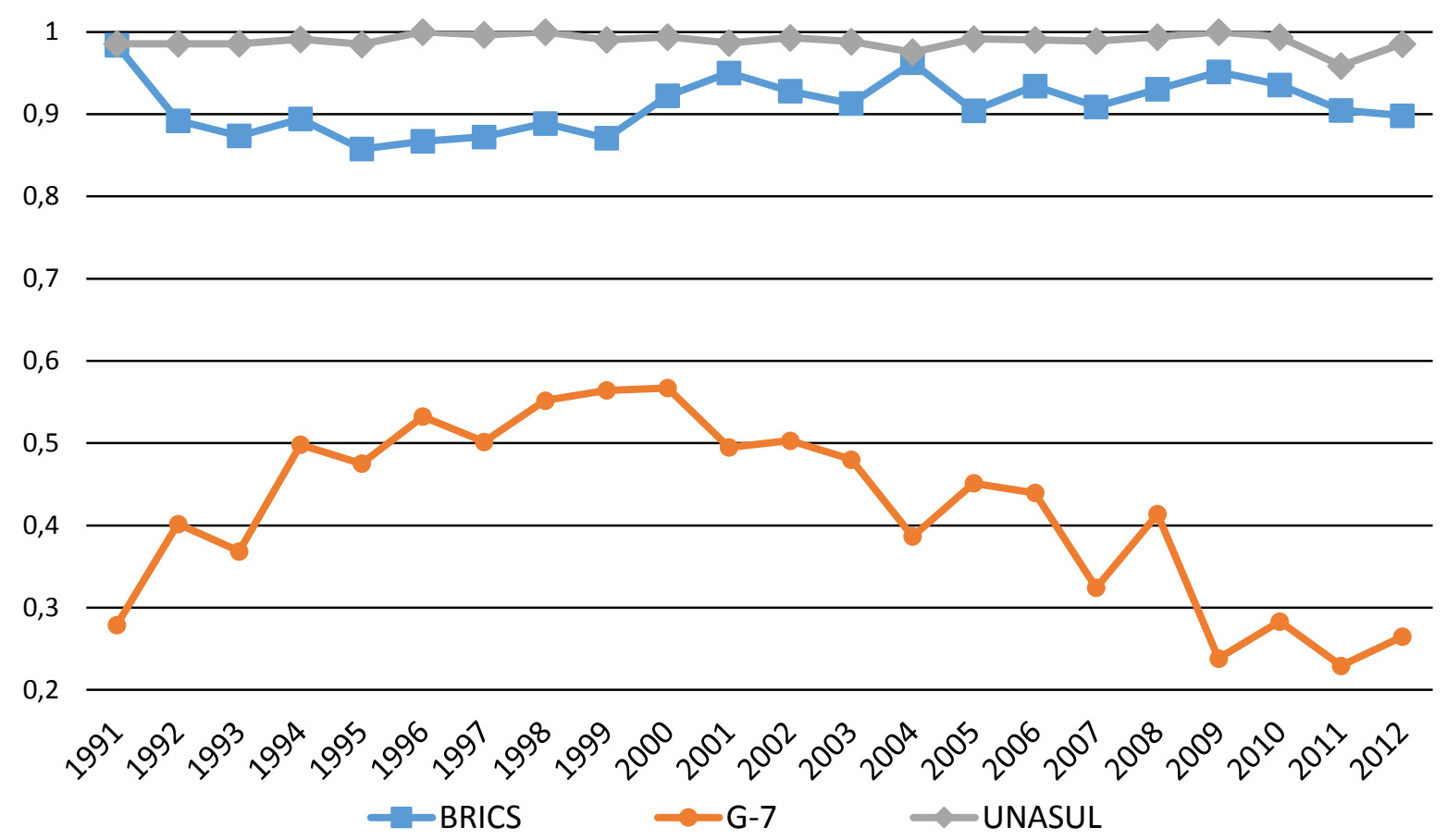

Fonte: Voeten (2012) e Voeten et al (2013)

Como pode ser visto a partir dos dados do Gráfico 2, não há grandes alterações no padrão de similaridade ente os votos do Brasil e os votos dos países do BRICS e da UNASUL ao longo década de 2000, seja no início do governo Lula - 2003 em diante, ou da maior formalização dos BRICS de 2006 em diante. Os dois grupos já apresentaram votações razoavelmente convergentes desde o final da Guerra Fria, indicando, inclusive, um perfil de votação bastante parecido entre o período FHC e o de Lula e Dilma.

A inflexão esperada a partir da criação dos BRICS, considerando o ano de 2006 quando ocorreu a primeira reunião ministerial entre Brasil, Rússia, Índia e China como o turning point, não aconteceu. E nem mesmo nos anos subsequentes, nos quais a institucionalidade dos BRICS começou a ser elaborada, é possível assinalar qualquer turning point no padrão de similaridade entre os votos do Brasil com os países dos BRICS.

\footnotetext{
${ }^{11}$ BRICS - Rússia, Índia, China e África do Sul; G-7 - Estados Unidos, Japão, Reino Unido, Alemanha, França, Itálica e Canadá; UNASUL - Argentina, Bolívia, Chile, Colômbia, Equador, Guiana, Paraguai, Peru, Suriname, Uruguai e Venezuela.
} 


\section{Leviathan | Cadernos de Pesquisa Política}

Por outro lado, a relação com os países do Brasil com os países do G-7 parece ter sido fortemente alterada a partir dos anos 2000. O formato de U-invertido da série indica que entre os anos de 1994 e 2002 houve maior convergência relativa entre o Brasil e os países do G-7. Tal resultado corrobora a tese defendida por Fonseca (1998) e Vigevani e Cepaluni (2007), na qual a política externa brasileira durante o período FHC fora consagrada pelo princípio da autonomia pela participação, enquanto no governo Lula a política se pautou pela autonomia pela diversificação de parceiros no sistema internacional.

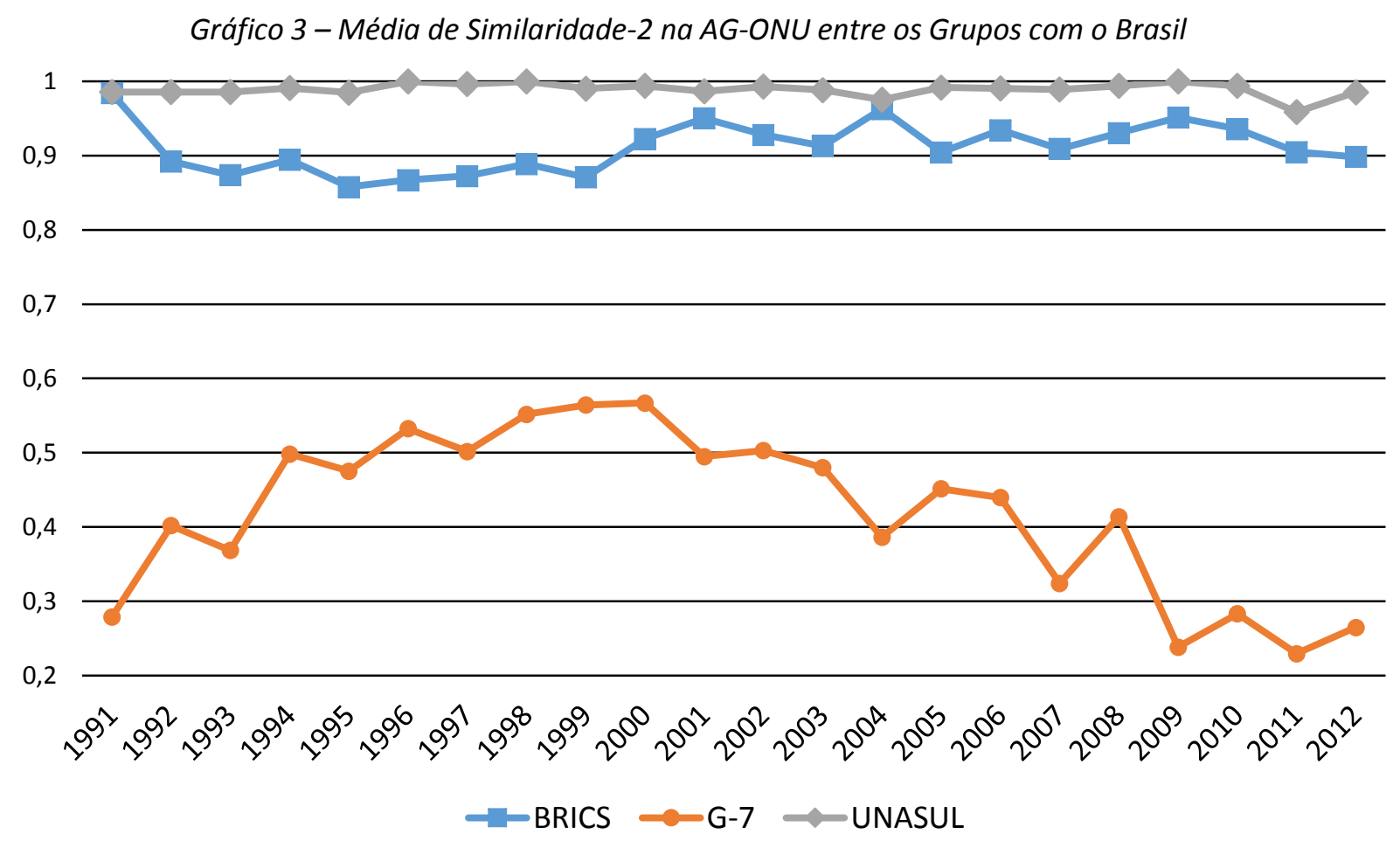

Fonte: Voeten (2012) e Voeten et al (2013)

O padrão dos dados do Gráfico 3 é bem semelhante ao encontrado anteriormente. Não há grandes alterações no padrão de similaridade ente os votos do Brasil e dos países do BRICS e da UNASUL, ainda que exista uma leve tendência ascendente a partir de 2003, com ápice em 2010 e posterior retorno no período Dilma (2011 e 2012) na curva dos BRICS. Já a curva da similaridade entre o Brasil e o G-7 mantém o mesmo formato U-invertido, indicando a adequabilidade dos conceitos de Fonseca e de Vigevani e Cepaluni.

A primeira grande conclusão a ser extraída destes gráficos é que embora os BRICS sejam uma coalizão de relevo no cenário internacional, a constituição deste grupo não afetou a orientação externa da política brasileira - assumindo que o padrão de votação da AG-ONU é 


\section{Leviathan | Cadernos de Pesquisa Política}

N. 11, pp.121-144, 2015

uma boa proxy para mensurar esta variável. O Brasil desde a década de 1990 já apresentava um perfil de votação alinhado com os países do BRICS e ainda mais com os países da UNASUL. A única mudança encontrada na análise dos dois gráficos é a confirmação que há uma reorientação do alinhamento brasileiro às nações do G-7.

Prosseguimos a análise no Gráfico 4, no qual apresentamos o padrão de similaridade-2 para cada um dos países do BRICS, mais a Argentina e EUA - os dois principais parceiros brasileiros na UNASUL e no G-7, respectivamente.

Gráfico 4 -Similaridade-2 na AG-ONU entre os países do BRICS, Argentina e Estados Unidos com o Brasil

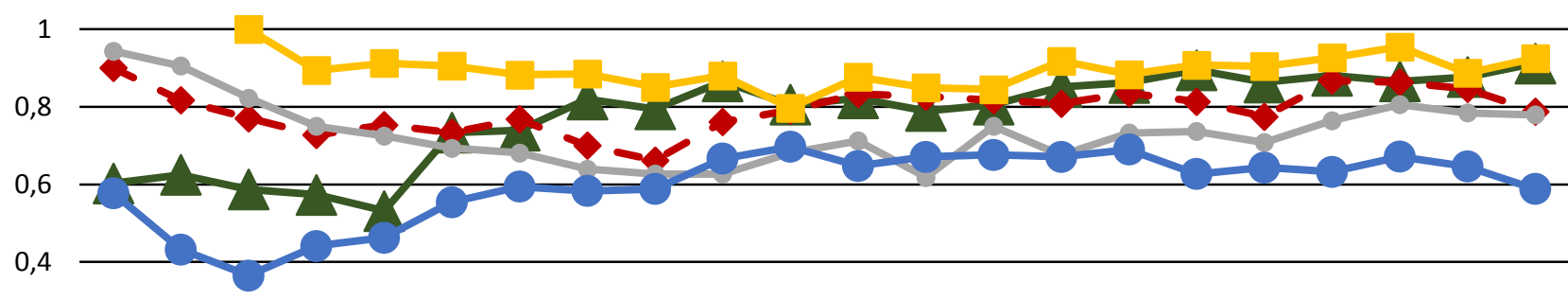

0,2

0

$-0,2$

$-0,4$

$-0,6$

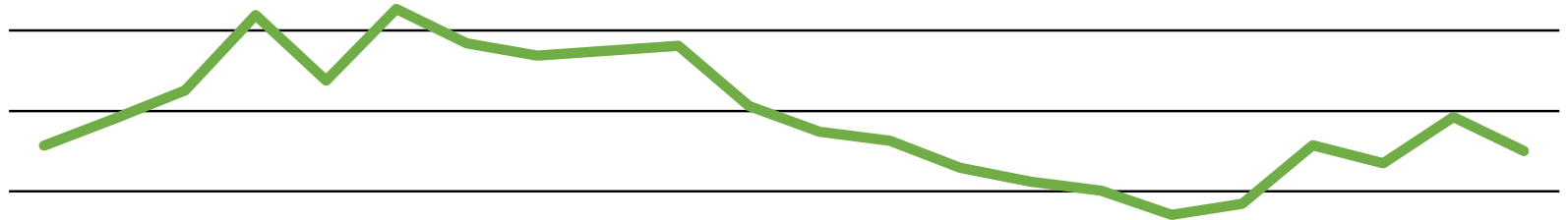

$-0,8$

1991199219931994199519961997199819992000200120022003200420052006200720082009201020112012

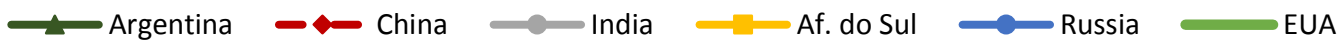

Fonte: Voeten (2012) e Voeten et al (2013)

No Gráfico 4, o que mais chama a atenção é a baixa convergência entre os votos brasileiros na AG-ONU com os votos americanos. Em todo o período analisando, o Brasil pouco convergiu com os EUA, apresentando ao longo das duas décadas índices negativos, não obstante durante o período da administração Cardoso a divergência entre os votos brasileiro e os votos americanos tenha sido menor.

No que se refere à convergência brasileira com os BRICS, o que chama atenção, outra vez, é o aparente pouco impacto da criação do grupo em 2006 no aumento ou diminuição da convergência entre os objetivos de política externa destes outros países com o Brasil. Existe 


\section{Leviathan | Cadernos de Pesquisa Política}

N. 11, pp.121-144, 2015

uma tendência crescente de maior convergência, mas o ângulo de crescimento desta tendência é baixo e não há indicação de que tenha sido afetado pela criação do grupo.

Caso optemos analisar esses dados por quinquênios, obtemos algumas informações relevantes. No primeiro quinquênio (1991-1995) a média de convergência é de 0.73 entre o Brasil e todos os outros membros dos BRICS. No segundo quinquênio (1996-2000), esta média continua no mesmo nível: 0.71 . No terceiro quinquênio (2001-2005) a média de convergência sobe para 0.76 . Finalmente, no último período abrangido pelos 7 anos após a criação dos BRICS para o qual temos dados (2006-2012) a média é de 0.785 . Logo, podemos concluir que ao longo dos últimos 10 anos, existe um processo de crescimento do grau de convergência das políticas externas dos países do BRICS em relação à política externa brasileira, mas esse crescimento na taxa de convergência não é forte.

Tabela 2. CONVERGÊNCIA QUINQUENAL - BRICS E ARGENTINA

\begin{tabular}{ccccccc} 
& Argentina & BRICS & China & Índia & África do Sul & Rússia \\
\hline $1991-1995$ & 0.584 & 0.733 & 0.794 & 0.829 & 0.935 & 0.456 \\
$1996-2000$ & 0.790 & 0.714 & 0.725 & 0.654 & 0.881 & 0.597 \\
$2001-2005$ & 0.815 & 0.758 & 0.815 & 0.688 & 0.857 & 0.673 \\
$2006-2012$ & 0.873 & 0.785 & 0.831 & 0.750 & 0.915 & 0.653 \\
$\begin{array}{c}\text { Taxa de Crescimento } \\
\text { 10 e 40 períodos }\end{array}$ & $49.5 \%$ & $7.1 \%$ & $4.7 \%$ & $-9.6 \%$ & $-2.2 \%$ & $43.2 \%$ \\
\hline
\end{tabular}

Fonte: Voeten (2012) e Voeten et al (2013)

Por outro lado, caso comparemos o crescimento da convergência de interesses entre Brasil e Argentina, isto deixa claro o quanto os BRICS ainda não afetaram sensivelmente o padrão de votação brasileiro na AG-ONU. No primeiro quinquênio a convergência com a Argentina é de reduzido 0.58 , enquanto no 2 o quinquênio este valor cresce para 0.79 , em seguida para 0.81. E no último período o valor é de impressionantes 0.87. Assim, entre 1991 e 2012 há um crescimento de 49\% na taxa de convergência entre as votações de Brasil e Argentina na AG-ONU, enquanto este crescimento na taxa de convergência entre as votações do Brasil e os BRICS - tomados em conjunto - é de apenas 7.1\%. Os dados sobre as taxas de convergência por quinquênios e a o crescimento destas taxas estão na Tabela 2.

Ademais, tanto na Tabela 2 como no Gráfico 4 é possível perceber que o padrão de evolução da convergência entre os votos na AG-ONU dos países do BRICS com o Brasil não é o mesmo. A Rússia parte de uma média de convergência muito baixa, ainda menor que o 


\section{Leviathan | Cadernos de Pesquisa Política}

N. 11, pp.121-144, 2015

patamar argentino, e termina em um nível de convergência ainda inferior que os outros BRICS, mas apresentando um crescimento geral nas duas últimas décadas de 43,3\%. Já as taxas de convergência com a China se mantém em mesmo patamar, variando muito pouco no período analisado, enquanto as taxas de convergência com Índia e África do Sul caem, ainda que minimamente, ao longo do período analisado.

A principal conclusão que se destaca desta análise é que a criação do grupo dos BRICS não afetou o comportamento em conjunto do Brasil com seus parceiros emergentes. Assumindo que as votações da AG-ONU são uma boa proxy para a avaliação dos interesses e orientações gerais da política externa dos diferentes países, é possível concluir que a formação e formalização dos BRICS como um fórum de cooperação internacional entre as potências emergentes não afetou a política externa brasileira tal qual fora esperado na literatura.

Inclusive encontramos poucas divergências entre o padrão de votação do Brasil e estes países ao longo dos governos de FHC e Lula, o que reduz em parte - pelo menos no que se refere à atuação brasileira na AG-ONU - o impacto que a adoção de um programa externo mais voltado para a cooperação Sul - Sul tenha tido na política externa brasileira.

\section{Considerações finais}

O objetivo deste artigo foi analisar o processo de formação da coalizão internacional dos BRICS e como esta coalizão alterou a política externa brasileira. Nas primeiras seções do trabalho discutimos a importância econômica dos BRICS, como esta coalizão tem como meta a reforma das instituições da arquitetura de governança da economia mundial.

Em seguida, apontamos como os BRICS responderam à falta de respostas por parte das econômicas mais desenvolvidas - organizadas no G-7 - com a criação de seus dois primeiros frutos institucionais: o Novo Banco de Desenvolvimento (NBD) e o Arranjo Contingente de Reserva (CRA); que são instituições competidores e que possuem a mesma função que duas das principais instituições de Bretton Woods - o Banco Mundial e o FMI, respectivamente. Este processo de formação institucional deixa claro o interesse dos países do BRICS na reconfiguração das relações econômicas globais. 


\section{Leviathan | Cadernos de Pesquisa Política}

N. 11, pp.121-144, 2015

Por fim, na segunda parte do trabalho, discutimos quais foram os efeitos da formação dos BRICS na política externa brasileira a partir da convergência entre os padrões de votação do Brasil e de seus parceiros na AG-ONU. Concluímos, enfim, que o surgimento dos BRICS não teve o impacto esperado na política externa brasileira, uma vez que os padrões de convergência permaneceram bastante semelhantes tanto no período anterior quanto no posterior à formação do grupo. Este resultado está em acordo com o achado de Ferdinand (2014) a respeito da grande estabilidade no padrão de convergência nas votações da AG-ONU, em especial da inexistência de diferença na convergência de votos entre os países membros dos BRICS antes e depois de formada a coalizão.

Finalmente, obtivemos evidências bastante interessantes sobre o fato de que apesar de não haver uma maior orientação terceiro mundista da política externa brasileira, tal qual era preconizado pelo discurso diplomático, há um evidente aumento na divergência dos votos brasileiros com os votos das democracias mais desenvolvidas do G-7, sobretudo em relação à convergência de votos brasileiros com o voto da potência estadunidense.

A partir das constatações destacadas, será possível no futuro estender a pesquisa com a análise da dinâmica das votações da AG-ONU em assuntos mais específicos, dada a grande amplitude de temas debatidos. Ferdinand (2014) já demonstrou que a convergência dos BRICS é menor em questões relacionadas a desarmamentos e direitos humanos. Posto isto, é importante verificar se a estabilidade encontrada neste trabalho reflete-se nas divisões temáticas. Além disso, uma continuação natural da pesquisa será analisar o comportamento dos países membros dos BRICS em outras organizações internacionais, como, por exemplo, as próprias negociações do sistema multilateral da Organização Mundial de Comercio. Finalmente, o rastreio das outras iniciativas apresentadas por dois ou mais parceiros dos BRICS no âmbito da própria AG-ONU é também outro campo aberto para futuros estudos. 


\section{Referências Bibliográficas}

Almeida, Paulo Roberto. 2010. O BRIC e a substituição de hegemonias: um exercício analítico (perspectiva histórico - diplomática sobre a emergência de um novo cenário global). In: BAUMANN, Renato (org.) O Brasil e os demais BRICs Comércio e Política. CEPAL. Escritório Brasil / IPEA.

Apolinário, Laerte. 2014. A governança das instituições financeiras internacionais: o caso do FMI e Banco Mundial. Dissertação de Mestrado apresentada ao Instituto de Relações Internacionais da Universidade de São Paulo.

Baumann, Renato; Araujo, Raquel; e Ferreira, Jhonathan. 2010. As Relações Comerciais do Brasil com os demais BRICs. In: BAUMANN, Renato (org.) O Brasil e os demais BRICs Comércio e Política. CEPAL. Escritório Brasil / IPEA.

Bijos, Leila e Guilhon, Erick Pessôa. 2014. BRICS, uma alternativa de poder? Revista de Direito Público, Londrina, v.9. n.1, p.9-54, jan./abr.

Cornetet, João Marcelo Conte. 2014. A política externa de Dilma Rousseff: Contenção na Continuidade. Revista Conjuntural Austral. Vol. 5, no 24.

Costa, Juliana Jerônimo. 2014. O fortalecimento das relações bilaterais e a apoio nos foros multilaterais: as relações Brasil-África (1995-2010). Tese de Doutorado apresentada ao Instituto de Relações Internacionais da Universidade de São Paulo.

Ferdinand, Peter. 2014. Rising powers at the UM: an analysis of the voting behavior of BRICS in the General Assembly. Third World Quarterly, vol. 35. no. 3, p. 376-391.

Flemes, Daniel. 2010. A visão brasileira da futura ordem global. Contexto Internacional. Vol. 32, n.2, julho/dezembro.

Fonseca Jr, Gelson. 1998. A legitimidade e outras questões internacionais. São Paulo: Paz e Terra.

Guimarães, Feliciano de Sá. 2014. The unintended Consequences of Non-Reforming Institutions: the creation of the BRICS Bank. Trabalho apresentado no 2o Seminário de Relações Internacionais - Os BRICS e as Transformações da Ordem Global organizado pela Associação Brasileira de Relações Internacionais - ABRI. João Pessoa, Paraíba.

Hertz, Monica e Dutra, Antonio. 2013. Os BRICS em Revisão de Literatura. Working Paper. Núcleo de Política Internacional e Agenda Multilateral. BRICS Policy Center. Centro de Estudos e Pesquisa. Abril.

Hurrel, Andrew. 2009. Hegemonia, liberalismo e ordem global: qual é o espaço para potências emergentes. In: NARLIKAR, Amrita; HURREL, Andrew, LIMA, Maria Regina Soares, HIRST, Monica, MACFARLANE, Neil; e FOOT, Rosemary. Os Brics e a Ordem Global. Editora FGV. São Paulo.

Kirton, John. 2008. From G8 2003 to G13 2010? The Heiligendamm Process's. In: COOPER, Andrew e ANTKIEWICKZ, Agata (ed.) Emerging Powers in Global Governance: Lessons from the Heiligendamm Process. Wilfrid Laurier University Press. Centre for International Governance Inovation.

Kissinger, Henry. 1999. A Diplomacia das grandes potências. Editora Saraiva. São Paulo. 


\section{Leviathan | Cadernos de Pesquisa Política}

N. 11, pp.121-144, 2015

Lijphart, Arend. 1963. The analysis of bloc voting in the General Assembly: A critique and a proposal. American Political Science Review, v. 57, n. 04, p. 902-917.

Lima, Maria Regina Soares. 2010. Brasil e polos emergentes do poder mundial: Rússia, Índia, China e África do Sul. In: BAUMANN, Renato (org.) O Brasil e os demais BRICs Comércio e Política. CEPAL. Escritório Brasil / IPEA.

Oliveira, Amâncio Jorge e Onuki, Janina. 2013. Coalizões e Coesão: Mercosul e BRICS na ONU. Centro de Estudos nas Negociações Internacionais. Universidade de São Paulo. Working Paper.

O'Neill, Jim. 2001. Building better global economic BRICs. New York: Goldman Sachs.

Marin-Bosch, Miguel. 1998. Votes in the UN General Assembly. Martinus Nijhoff Publishers.

Marin-Bosch, Miguel. 1987. How nations vote in the General Assembly of the United Nations. International Organization, v. 41, n. 04, p. 705-724.

Ramos, Leonardo. 2014. Potências médias emergentes e reforma da arquitetura financeira mundial?: Uma análise do BRICS no G20. Revista de Sociologia e Política, Curitiba, v. 22, n. 50, p. 49-65, June.

Selcher, Wayne A. 1978. Brazil's multilateral relations: between first and third worlds. Westview Pr.

Stuenkel, Oliver. 2014a. Brazilian Foreign Policy: Game over. Post-Western World: How Are Emerging Powers Changing The World.

Stuenkel, Oliver. 2014b.Is Brazil abandoning its global ambitions? Post-Western World: How Are Emerging Powers Changing The World.

Stuenkel, Oliver. 2012. Can the BRICS Co-operate in the G-20? A View from Brazil. Occasional Paper no. 123. Economic Diplomacy Programme. SAllA - South African Institute of International Affairs.

Thacker, Strom. 1999. The High Politics of IMF Lending. World Politics. 52: 38-75.

Tomlin, BW. 1985. Measurement Validation: Lessons from the Use and Misuse of UN General Assembly Roll-Call Votes. International Organizations. 39(1). p. 189-206.

Vigevani, Tullo; Cepaluni, Gabriel. 2007. A política externa de Lula da Silva: a estratégia da autonomia pela diversificação. Contexto internacional, v. 29, n. 2, p. 273-335.

Voeten, Erik. 2012. Data and Analyses of Voting in the UN General Assembly. Available at SSRN: http://ssrn.com/abstract=2111149

Voeten, Erik; Strezhnev, Anton; Bailey, Michael. 2013. "United Nations General Assembly Voting Data", http://hdl.handle.net/1902.1/12379

Voeten, Erik. 2000. Clashes in the Assembly. International Organization, v. 54, n. 02, p. 185-215. 
Tramitação do artigo na revista Submetido: 09/05/2015

Revisões requeridas: 06/07/2015 Versão revista: 28/08/2015

Aceito: 20/09/2015 